\title{
Comunicação
}

\section{Tratamento cirúrgico dos insulinomas - Estudo de 59 casos}

\author{
M.C.C. Machado, J .J Ukemura, J .E.M. da Cunha, S. Penteado, T. Bacchella, E.E. Abdo, A. Montagnini, \\ P. HERMAN, M.A.C. MACHADO, H.W. PINOTTI
}

Disciplina de Cirurgia do Aparelho Digestivo da Faculdade de Medicina da Universidade de São Paulo, São Paulo, SP.

RESUMO - Após a confirmação clínica e laboratorial de hiperinsulinismo, o principal problema consiste na localização precisa da lesão no parênquima pancreático, propiciando tratamento cirúrgico adequado.

Ов ет тіvo. Analisar os métodos utilizados para o diagnóstico e localização pré e intra-operatório dos insulinomas, bem como as técnicas e os resultados do tratamento cirúrgico.

Métodos. Foram estudados 59 casos consecutivos de insulinoma submetidos a intervenção cirúrgica. Cada um dos métodos utilizados para a localização pré-operatória dessas lesões foi avaliado quanto à sua eficiência em confronto com os achados intra-operatórios. A palpação do pâncreas, isoladamente ou associada à ultra-sonografia intra-operatória, como métodos de localização dos insulinomas, foi também estudada. Os tipos de intervenção cirúrgica foram analisados quanto aos seus resultados imediatos e tardios.

Resultados. Dos 59 insulinomas, 55 eram benignos e quatro, malignos. Dos métodos utilizados para a localização pré-operatória, a ultra-sonografia foi eficiente em $28,1 \%$ dos casos, a tomografia computadorizada em $25 \%$, a ultra-sonografia endoscópica em $27,2 \%$, a arteriografia seletiva em $54,1 \%$ e a col heita de amostras de sangue portal para dosagem de insulina em $94,4 \%$ dos casos.

\section{NTRODUÇÃO}

Desde 1927, quando foi descrito pela primeira vez por Wilder et al. ${ }^{1}$, o insulinoma do pâncreas tem sido objeto de inúmeras publicações referentes não só ao diagnóstico ${ }^{2,3}$ como, também, à sua localização no parênquima pancreático ${ }^{3-9}$.

Após confirmado, do ponto de vista clínico e laboratorial, o diagnóstico de hiperinsulinismo, o principal problema a ser enfrentado pelo cirurgião se refere à localização exata desses tumores, quer no pré quer no intra-operatório.

Os insulinomas, ao contrário do que se pensava anteriormente, não têm localização preferencial na cauda do pâncreas, mas se distribuem uniformemente pelos diversos segmentos do órgão ${ }^{10}$. As-
A palpação bidigital, durante a intervenção cirúrgica, localizou as lesões em $54 / 55$ casos $(98,2 \%)$. A ultra-sonografia intra-operatória foi decisiva em apenas um caso.

Cinco doentes apresentavam neoplasia endócrina múltipla tipo I e em todos as lesões pancreáticas eram múltiplas.

Foram efetuadas 29 enucleações e 32 ressecções pancreáticas nos doentes com lesões benignas. Os doentes com lesões malignas foram submetidos a ressecções pancreáticas e qui mioterapia. Não houve mortalidade, porém observaram-se complicações (fístulas) em 29/59 casos. Os resultados foram bons em $\mathbf{9 8 , 1 \%}$ dos doentes com lesões benignas. Apenas um dos doentes com lesões malignas sobreviveu cinco anos. Três doentes portadores de lesões benignas e submetidos a ressecções pancreáticas evoluíram com diabetes tardiamente.

Conclusões. A localização pré-operatória não é absolutamente necessária desde que a palpação bidigital associada a ultra-sonografia intra-operatória permite a localização de todas as lesões. As enucleações devem ser utilizadas, quando possível, de preferência às ressecções pancreáticas nas lesões benignas.

UNITERMOS: Tumor de pâncreas. Hipoglicemia. Tumor de ilhotas.

sim, a realização de pancreatectomia corpo-caudal às cegas, para o tratamento da doença, não mais se justifica. A localização precisa da lesão é, portanto, essencial para seu tratamento cirúrgico.

Dos métodos de imagem disponíveis, a arteriografia já foi considerada o melhor método ${ }^{9}$, porém outros autores, anal isando dados da literatura, não conseguiram comprovar esses fatos ${ }^{10}$. Novos métodos de diagnóstico e de localização dessas lesões, como a colheita por punção percutânea de amostras de sangue portal para determinação de insulina, a ultra-sonografia endoscópica, a tomografia computadorizada helicoidal, têm sido utilizados, porém nenhum deles, isoladamente, é capaz de localizar os insulinomas em todas as situações, principalmente nos casos de lesões múlti- 
plas, como acontece na neoplasia endócrina múltipla tipo ${ }^{11}$.

O objetivo da presente publicação é apresentar as técni cas e os resultados do tratamento ci rúrgi co de 59 portadores de insulinoma, bem como os métodos utilizados para o diagnósti co e localização dessas lesões.

\section{MATERIAL E MÉTODOS}

Foram analisados (de 1975 a 1996) 59 doentes, sendo 36 mulheres $(61,0 \%)$ e 23 homens $(38,9 \%)$, ou seja, uma rel ação de 1,5:1. A idade variou de 12 a 70 anos, com média de 36,3 anos. Vinte e quatro doentes $(40,6 \%)$ apresentavam idade inferior a 30 anos e $32(54,2 \%)$ tinham idade entre 30 e 60 anos. A quase totalidade dos doentes $(94,8 \%)$ apresentava idade inferior a 60 anos. Somente três doentes tinham idade acima de 60 anos (5,0\%).

A duração da sintomatologia está discriminada na tabela 1.

Com respeito à sintomatologia, todos os doentes desta casuística apresentavam sintomas neuropsiquiátricos, incluindo desde al terações do comportamento, confusão mental e hipersonia, até convulsões e coma. Apenas seis doentes (10,1\%) apresentavam predominância de sintomas cardiovasculares.

Um doente foi identificado 40 dias após o início da sintomatologia, enquanto um outro, cerca de 15 anos após o início do quadro.

Dos métodos para o diagnóstico de hiperinsulinismo, o jejum prolongado com determinações seriadas de glicemia e insulinemia foi utilizado em todos os casos. Em apenas três doentes utilizou-se também a curva de tolerância à glicose, enquanto o teste de tol butamida foi empregado em três doentes desta casuística. Os testes e determinações hormonais realizados nos portadores de neoplasia endócrina múltipla para o diagnóstico de outras lesões serão objeto de outra publicação. Peptídeo-C foi determinado em quatro doentes desta série, tendo sido objeto de publicação anterior ${ }^{12}$.

Vários métodos de imagem foram utilizados para a localização pré-operatória dos insulinomas. A arteriografia seletiva do tronco celíaco e da artéria mesentérica superior, utilizada nos primeiros casos (fig. 1), foi ulteriormente substituída pela ultra-sonografia convencional, tomografia computadorizada do abdome, portografia com coIheita de sangue portal (fig. 2) e, mais recentemente, ultra-sonografia endoscópica e ressonância nuclear magnética.

Todos os doentes desta série foram submetidos a tratamento cirúrgico. A incisão empregada em todos

\begin{tabular}{|ccc|}
\hline Tabela 1 - Tempo de duração dos sintomas & \\
\hline Tempo de duração dos sintomas & Número de doentes & $\%$ \\
até 1 ano & 27 & 45,76 \\
entre 1 - 5 anos & 21 & 35,59 \\
acima de 5 anos & 11 & 18,64 \\
\hline
\end{tabular}

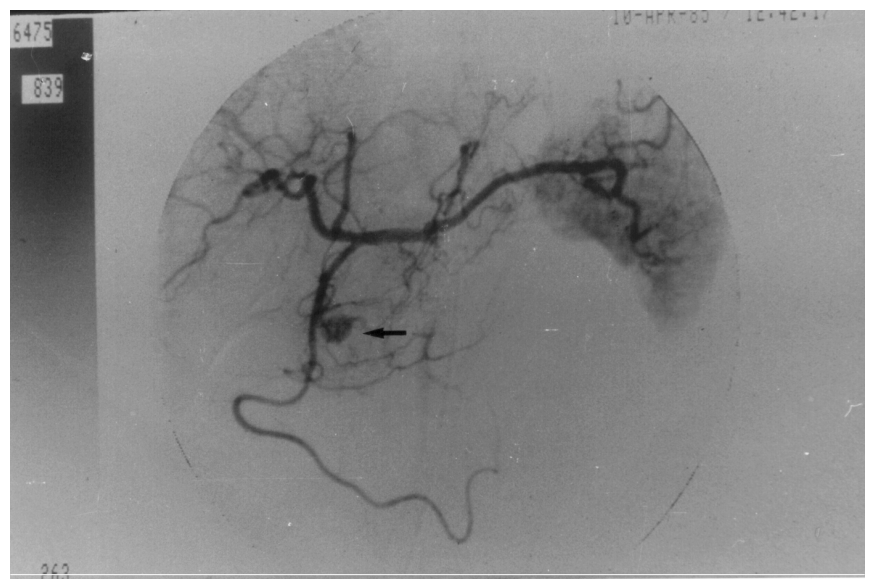

Fig. 1 - Arteriografia sel etiva do tronco celíaco revelando tumor hipervascularizado (seta) na cabeça do pâncreas.

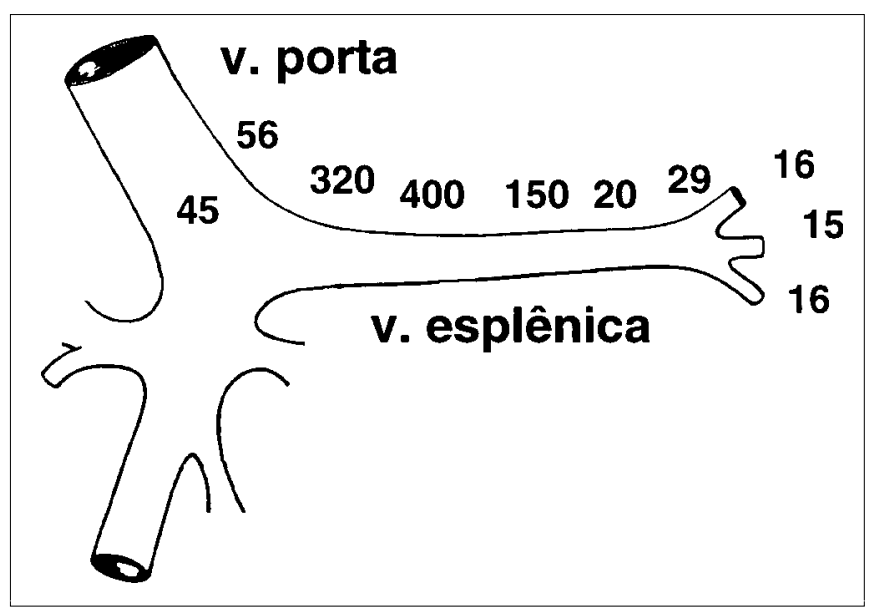

Fig. 2 - Determinação de insulina (expressa em $\mu \mathrm{U} /$ $\mathrm{mL}$ ) em amostras de sangue portal. Verifica-se nível elevado de insulina $(400 \mu \mathrm{U} / \mathrm{mL})$ na veia esplênica na região do corpo do pâncreas.

os casos foi a transversa subcostal bilateral. O epíploon gastrocólico foi seccionado entre ligaduras, dando acesso à retrocavidade. O pâncreas foi dissecado de modo a poder ser pal pado bidigitalmente em toda sua extensão. A cauda, em al guns casos, só pôde ser perfeitamente visualizada e palpada após descolamento e rebaixamento do ângulo esplênico do colo. A manobra de Kocher foi realizada em todos os casos para facilitar não só a pal pação, como também a enucl eação dos tumores cefálicos. 
Nos últimos dez casos, a ultra-sonografia intraoperatória foi utilizada para auxiliar na localização das lesões no parênquima pancreático e na avaliação de sua relação anatômica com o ducto pancreático principal e grandes vasos.

Nos tumores localizados na cabeça do pâncreas e, perifericamente, no corpo e cauda, praticou-se enucl eação das lesões.

Quando os tumores se local izavam mais profundamente no corpo ou cauda ou eram múltiplos, executou-se pancreatectomia corpo-caudal com esplenectomia. Nos últimos cinco doentes, incluindo um doente jovem, a ressecção corpo-caudal foi efetuada com preservação do baço e da artéria e veia esplênicas.

Em doentes com lesões cefálicas malignas ou impossíveis de serem enucleadas, efetuou-se duodenopancreatectomia pela técnica utilizada pelo serviço ${ }^{13}$, que consiste na utilização de duas alças jejunais isoladas para a reconstrução de trânsito biliar e pancreático ${ }^{13}$.

\section{RESULTADOS}

O teste laboratorial que estabeleceu o diagnóstico de insulinoma em todos os doentes foi o jejum prolongado e a determinação da insulinemia. Este teste foi positivo em $100 \%$ dos casos desta série.

Os resultados dos exames utilizados para a localização pré-operatória dos insulinomas estão resumidos na tabela 2.

$\mathrm{Na}$ arteriografia, o único caso de falso positivo deveu-se a interpretação errônea de um baço acessório como insulinoma. Na portografia, o erro diagnóstico resultou de colheita de amostra de sangue portal efetuada seletivamente em veia pancreática, revelando níveis el evados de insulina em paciente sem insulinoma e com hipoglicemia factícia (fazia uso de hipoglicemiantes orais devido a problemas psíquicos).

Houve três complicações relacionadas aos métodos para localização dos insulinomas (tabela 3). Foram controladas mediante tratamento cirúrgico. Dos 59 insulinomas estudados, 55 eram benignos e quatro, malignos (6,7\%). Dos tumores benignos, 46 eram simples e nove, múltiplos (15,2\%).

Os tumores benignos únicos localizavam-se 16 na cabeça, 16 no corpo, sete na cauda e sete no processo uncinado (fig. 3 ).

Dos insulinomas múltiplos encontrados em nove doentes, quatro lesões se assestavam na cabeça do pâncreas, sete no corpo e 22 na cauda, ou seja, $87,8 \%$ dos nódulos tumorais, nas lesões múltiplas, encontravam-se no corpo e cauda do pâncreas e apenas $12,1 \%$ na cabeça. Os tumores múltiplos variaram de 2 a 10 por doente.

\begin{tabular}{|c|c|c|c|c|}
\hline \multicolumn{5}{|c|}{ Tabela 2 - Localização pré-operatória dos insulinomas } \\
\hline & $\begin{array}{c}\text { № de } \\
\text { pacientes }\end{array}$ & $\begin{array}{l}\text { Positivos } \\
(\%)\end{array}$ & $\begin{array}{c}\text { Falso } \\
\text { positivo }\end{array}$ & $\begin{array}{c}\text { Falso } \\
\text { negativo } \\
\mathbf{N}(\%)\end{array}$ \\
\hline Ultra-sonografia & 32 & $9(28,1)$ & 0 & $21(71,89)$ \\
\hline Arteriografia seletiva & 24 & $13(54,1)$ & 1 & $11(45,8)$ \\
\hline $\begin{array}{l}\text { Portografia e colheita } \\
\text { de sangue portal } \\
\text { Tomografia }\end{array}$ & 18 & $17(94,4)$ & 1 & $1(5,5)$ \\
\hline $\begin{array}{l}\text { computadorizada } \\
\text { Ultra-sonografia }\end{array}$ & 28 & $7(25)$ & 0 & $21(75)$ \\
\hline endoscópica & 11 & $3(27,2)$ & 0 & $8(72,7)$ \\
\hline Ressonância magnética & ca 6 & $1(16,6)$ & 0 & $5(83,3)$ \\
\hline
\end{tabular}

Tabela 3 - Complicações dos exames para localização dos insulinomas

\begin{tabular}{|lll|}
\hline \multicolumn{1}{|c|}{ Exame } & \multicolumn{1}{c|}{ Complicações } \\
Ultra-sonografia endoscópica & Perfuração do esôfago & 1 \\
Colheita de sangue portal & Hemorragia intraperitonial & 1 \\
& Coleperitônio & 1 \\
\hline
\end{tabular}

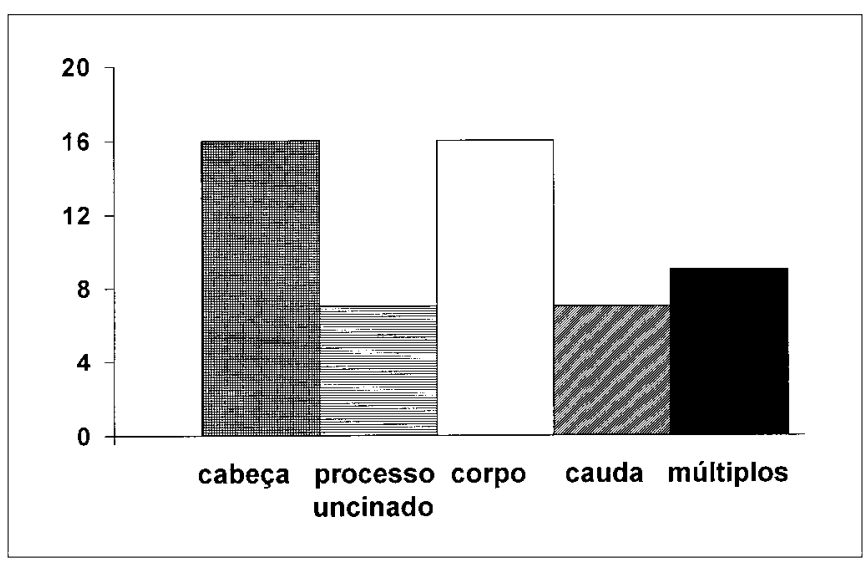

Fig. 3 - Localização dos insulinomas benignos nos diversos segmentos do pâncreas.

Dos doentes com tumores múltiplos, cinco apresentavam neoplasia endócrina múltipla (NEM I). Nenhum doente com essa síndrome apresentou tumor único nesta casuística.

Dos 55 doentes com tumores benignos, 54 foram corretamente localizados durante a primeira intervenção. Em apenas um caso, já previamente submetido a pancreatectomia corpo-caudal às cegas em outro serviço, não se conseguiu localizar a lesão, na primeira intervenção, em virtude do processo inflamatório presente. Numa segunda reoperação, com a utilização da ultra-sonografia intra-operatória, esta lesão foi removida. Em todos os outros casos, a palpação intra-operatória localizou corretamente a lesão. 


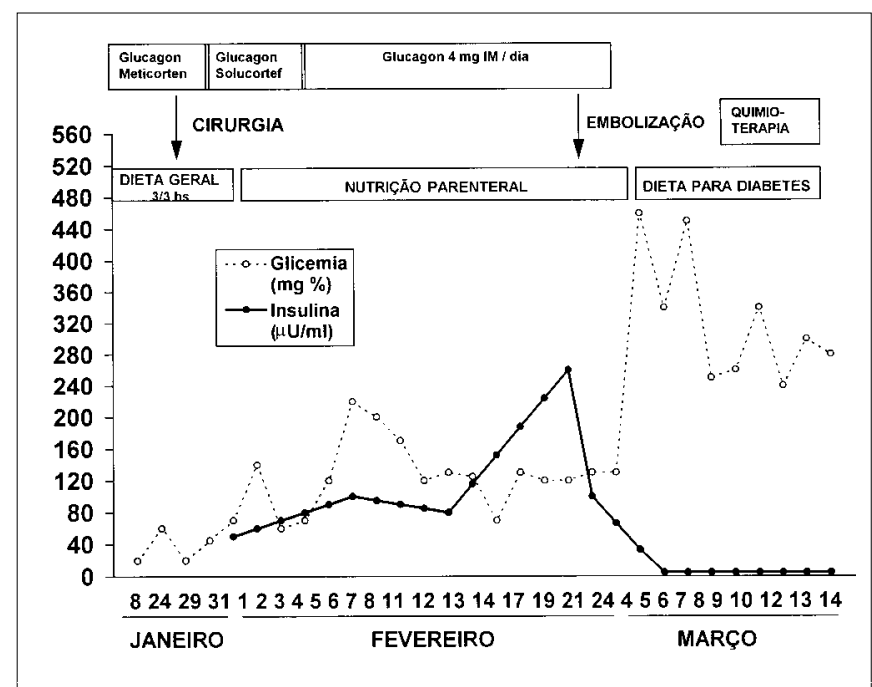

Fig. 4 - Evolução de doente portador de insulinoma maligno submetido a ressecção pancreática e posterior mente a embolização hepática e quimioterapia. N otase, após a embolização hepática, redução da insulinemia e elevação da glicemia.

Tabela 4-Resultados imediatos do tratamento cirúrgico dos insulinomas benignos

\begin{tabular}{|c|c|c|c|c|c|}
\hline $\begin{array}{c}\text { Tipo de } \\
\text { intervenção }\end{array}$ & № & $\begin{array}{c}\text { Fístula } \\
\text { pancreática }\end{array}$ & $\begin{array}{l}\text { Lesão de } \\
\text { colédoco }\end{array}$ & $\begin{array}{l}\text { Fístula } \\
\text { biliar }\end{array}$ & Óbito \\
\hline Enucleação & 22 & 9 & 1 & 1 & 0 \\
\hline $\begin{array}{l}\text { Pancreatectomia } \\
\text { corpo-caudal }\end{array}$ & 25 & 15 & - & - & O \\
\hline $\begin{array}{l}\text { Pancreatectomia } \\
\text { corpo-caudal } \\
\text { associada a }\end{array}$ & & (1) & 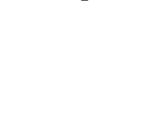 & 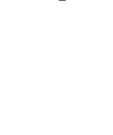 & 0 \\
\hline $\begin{array}{l}\text { enucleção } \\
\text { Duodeno- }\end{array}$ & 7 & 5 & - & - & - \\
\hline pancreatectomia & 1 & - & - & - & - \\
\hline Total & 55 & 29 & 1 & 1 & 0 \\
\hline
\end{tabular}

Com respeito ao tamanho dos tumores benignos ressecados, nove apresentavam dimensões entre 0,5 e $1 \mathrm{~cm}$, enquanto nos demais as dimensões variaram entre 1 e $3,5 \mathrm{~cm}$.

Um dos doentes desta série apresentou súbita melhora da hipogl icemia al guns dias antes da intervenção. À cirurgia, apresentava hemorragia intratumoral, sendo a lesão ressecada sem complicações.

Os resultados imediatos do tratamento cirúrgico dos insulinomas benignos em relação ao tipo de intervenção realizada constam da tabela 4. Nos últimos cinco casos de ressecção pancreática o baço foi preservado.
Fístula biliar e lesão do colédoco aconteceram no mesmo doente, portador de insulinoma de $3,0 \mathrm{~cm}$ de diâmetro profundamente localizado na cabeça do pâncreas, que foi, posteriormente, reoperado e submetido a derivação biliodigestiva.

Todos os doentes tiveram monitorização da glicemia durante a cirurgia, ocorrendo hipergl icemia sempre que a lesão ou lesões foram totalmente ressecadas. Isto aconteceu nos 55 doentes com lesões benignas e em um com doença maligna.

No ponto de vista de seguimento tardio dos doentes com tumores benignos, verificou-se que três dos submetidos à pancreatectomia corpo-caudal desenvolveram diabetes (10,7\%). Um doente, submetido a enucleação do tumor, apresentou recidiva dos sintomas de hipoglicemia tardiamente. $\mathrm{Na}$ reoperação, não se conseguiu localizar nenhuma lesão. Apresenta, atualmente, hipoglicemia leve, controlada com dieta.

Três doentes com seqüelas neurológicas, já observadas no pré-operatório, mantiveram-se sem alteração delas no pós-operatório. Dois deles tinham rebaixamento mental acentuado e um outro, lesão neurológica periférica leve.

Dos tumores malignos, dois foram submeti dos a ressecção pancreática (duodenopancreatectomia em um e pancreatectomia subtotal no outro), associada a embolização da artéria hepática e quimioterapia com 5-fluorouracil e estreptozotocina. Nos outros dois casos, em um foi realizada pancreatectomia subtotal e ressecção de gânglio metastático, enquanto no outro foi realizada enucl eação do tumor, ooforectomia bilateral (metástases nos ovários), ressecção de inúmeras metástases peritoniais e quimioterapia pós-operatória.

$\mathrm{E} m$ relação às dimensões desses tumores, dois apresentavam mais de $5 \mathrm{~cm}$ de diâmetro, um cerca de $1,5 \mathrm{~cm}$ e $o$ outro apenas $0,5 \mathrm{~cm}$.

E $m$ relação aos tumores mal ignos, não se observaram complicações pós-operatórias imediatas.

Os dois doentes com metástases hepáticas tiveram, após embolização pós-operatória da artéria hepática, regressão transitória da sintomatologia, porém faleceram antes de decorridos dois anos após a intervenção, com recidiva da sintomatologia hipoglicêmica. U m outro faleceu com recidiva de tumor no pâncreas. Este doente, curiosamente, apresentava neoplasia pancreática de dimensões mínimas, com metástases ovarianas e peritoniais com dois tipos de células, um que expressava antígeno carcinoembriônico (CEA) e outro que produzia insulina. Após remoção praticamente completa de todas as metástases e quimioterapia com estreptozotocina e 5-fluorouracil, houve regressão do hiperinsulinismo. A doente ficou 
assintomática por cerca de três anos, quando retornou ao serviço com neoplasia do pâncreas e icterícia. À reoperação, o tumor era irressecável, tendo a biópsia demonstrado células tumorais expressando apenas CEA. Apenas um doente com insulinoma maligno, submetido a pancreatectomia subtotal e ressecção de metástase ganglionar única, está vivo, tendo sido operado posteriormente de neoplasia da paratiróide. Esse doente era portador da síndrome de neoplasia endócrina múltipla (NEM I).

\section{DISCUSSÃO}

Os insulinomas constituem os tumores de ilhotas mais freqüentes, constituindo cerca de $17 \%$ de todos os tumores neuroendócrinos do trato digestivo ${ }^{14}$. São tumores raros, afetando 4/1.000.000, porém é provável que esta freqüência seja subestimada ${ }^{8}$.

No presente estudo, $61,0 \%$ dos doentes eram do sexo feminino, o que está de acordo com dados de muitas séries ${ }^{8,10}$. Ocorre em qual quer idade, porém a grande maioria situa-se entre 30 e 60 anos de idade $^{15}$. Nesta casuística, $54,2 \%$ dos doentes estavam nessa faixa etária e 94,8\% apresentavam idade inferior a 60 anos.

Do ponto de vista diagnóstico, neste trabalho, $46,4 \%$ dos doentes tiveram o diagnóstico estabel ecido com até um ano de sintomatologia, enquanto os restantes só foram diagnosticados após um ano, dos quais $17,8 \%$ tiveram o diagnóstico firmado mais de cinco anos após o início da sintomatologia. O retardo diagnóstico está presente em outros trabalhos, podendo atingir até 15 anos $^{8,15}$, como aconteceu em um caso da presente série.

Esta dificuldade diagnóstica resultou, em três doentes, em lesões neurológi cas irreversíveis, sendo duas delas extremamente graves.

O diagnóstico foi firmado em todos os casos por mei o da demonstração de hipoglicemia e secreção inadequada de insulina durante períodos variáveis de jejum. A determinação simultânea de peptídeo $C$ pode ser útil no diagnóstico de insulinoma em doentes nos quais se suspeita existir injeção clandestina de insulina ${ }^{16}$. Este teste foi feito em um número pequeno de casos. Teste de estimulação por tolbutamida foi utilizado em número mínimo de doentes, dado o risco de hipoglicemia grave ${ }^{16}$.

Do ponto de vista da localização dessas neoplasias no parênquima pancreático, vários métodos têm si do propostos. A tabela 2 mostra os resul tados da utilização dos diversos métodos disponíveis. A ultra-sonografia convencional realizada em 30 doentes foi positiva em apenas $28,1 \%$ dos casos. Em outras séries, a sensibilidade deste método varia de $23 \%$ a $62 \% \%^{3,6}$. A técni ca é operador-dependente e, apesar de não ser muito sensível, permanece como o método inicial a ser utilizado na localização da lesão. Sua sensibilidade varia de acordo com as dimensões e localização do tumor, sendo maior quando os tumores se localizam na cabeça e corpo do pâncreas ${ }^{3}$.

A tomografia computadorizada de abdome apresentou sensibilidade igual ou menor que a da ultra-sonografia6,17. Neste estudo, a tomografia localizou a lesão em apenas $25 \%$ dos casos, eficácia semel hante à observada por outros autores. Baixa sensibilidade (30\%) da tomografia computadorizada de abdome foi observada em publicação recente da Mayo Clinic ${ }^{6}$. É possível, no entanto, que os novos tomógrafos helicoidais sejam mais eficientes no diagnóstico dessas lesões.

A arteriografia seletiva do abdome, que já foi considerada como método de escolha na localização dessas lesões, com sensibilidade de até $95 \%{ }^{18}$, localizou o insul inoma em apenas $54,1 \%$ dos casos, resultados estes semel hantes aos obtidos recentemente por outros autores ${ }^{3,6,7}$. Em trabalho de revisão da literatura, Stefanini et al. ${ }^{10}$, avaliando resultados da arteriografia, obtiveram a média de $65,9 \%$ de positividade.

A ultra-sonografia endoscópica, utilizada inicialmente em nove doentes-casuística, foi diagnosticada em apenas um caso. Recentemente, com maior experiência, o diagnóstico destas lesões foi positivo em dois dos dois casos em que foi realizada. É possível que no futuro este exame possa atingir maior precisão. A ultra-sonografia intraoperatória, utilizada nesta série nos úl timos casos, foi decisiva em apenas um doente, que havia sido submetido a pancreatectomia corpo-caudal, tornando o restante do órgão de difícil palpação pela fibrose existente.

Neste estudo, a pal pação intra-operatória conseguiu localizar corretamente 54 dos 55 casos de lesões benignas. Estes resultados estão de acordo com a experiência de Menegaux et al. ${ }^{3}$ Outros autores, no entanto, referem que a exploração cirúrgica fal hou em $10-25 \%$ dos casos $^{19-21}$. Por estas razões, vários autor es recomendam estudos exaustivos no pré-operatório, no sentido de localizar corretamente tais lesões ${ }^{19}$.

A colheita percutânea de amostras de sangue portal, para determinação dos níveis de insul ina ${ }^{22}$, foi utilizada em 18 doentes, sendo possível localizar a lesão em 17 casos (94,4\%). A pesar de eficiente, o método apresentou um falso positivo e dois casos de complicações graves. A morbidade do 
procedimento, portanto, não é desprezível, podendo atingir $22 \%^{3}$. Uns têm utilizado este método com alta efi ciência ${ }^{17}$, enquanto outros só conseguiram $75 \%$ de positividade ${ }^{23}$.

Alguns autores acreditam que, apesar do entusiasmo na utilização do método de colheitas de amostras de sangue portal na localização dessas lesões, este método apenas determina o segmento do pâncreas onde a lesão, provavelmente, se assesta, não desobrigando de qual quer modo o cirurgião de procurar palpá-la durante a intervenção9 ${ }^{9}$ No estudo de Norton et al. ${ }^{23}$, apenas um doente, realmente, se beneficiou dessa metodologia. Com efeito, todos os doentes nos quais utilizamos esta técnica as lesões foram perfeitamente identificadas durante o ato cirúrgico pela palpação bidigital, não sendo o método decisivo em nenhuma situação.

Em virtude desse fato, a colheita de sangue portal para localização dos insulinomas não faz parte, atualmente, da rotina pré-operatória na investigação dos nossos casos. E m nossa experiência, a colheita de sangue portal só se justificaria em doente previamente submetido a ressecção pancreática ou exploração cirúrgica infrutífera com recidiva ou manutenção da sintomatologia.

A utilização de colheita de sangue portal poderia ser útil, no entanto, na identificação de casos de nesidioblastose ou hiperplasia de ilhotas, situações estas extremamente raras em indivíduos adultos ${ }^{9}$.

A palpação bidigital, realizada após adequada mobilização de toda a glândula, é fundamental para a localização dessas lesões. Nas mãos de cirurgiões experientes, uma alta porcentagem desses tumores é detectada durante a intervenção cirúrgica ${ }^{3}$, o que levou, até mesmo, alguns a dispensarem a utilização de métodos de localização pré-operatória ${ }^{4}$. $\mathrm{Na}$ experiência de Van Heerden et al. ${ }^{9}$ utilizando ultra-sonografia intra-operatória e pal pação, em quatro doentes as lesões foram localizadas excl usi vamente pel a pal pação intra-operatória. A associação da palpação bidigital e ultrasonografia intra-operatória constitui, na experiência de vários autores, o melhor método para localização dessas lesões ${ }^{9,11,24}$.

Nas situações de síndrome de neoplasia endócrina múltipla (NEM-1), as lesões são, usualmente, múltiplas ${ }^{25}$ e, freqüentemente, difíceis de serem completamente identificadas, quer no pré quer no intra-operatório. Com efeito, nos casos de síndrome adenomatosa múltipla, as lesões foram sempre múltiplas e, na grande maioria (87,8\%), localizadas no corpo e cauda do pâncreas. A identificação perfeita de cada uma das lesões, principalmente as localizadas no corpo e cauda do pâncreas, não é absolutamente necessária desde que a filosofia da terapêutica cirúrgica, nestes casos, difira da utilizada nos insulinomas habituais. Assim, em todos os casos de síndrome de neoplasia endócrina múlti pla, foi realizada pancreatectomia subtotal, procedimento recomendado por vários autores ${ }^{25-27}$, associado ou não à enucleação de lesões Iocalizadas na cabeça do pâncreas.

A cirurgia constitui o único método de cura da doença, pela excisão local dos tumores ou ressecção segmentar do pâncreas.

A exploração do pâncreas é sempre executada por meio de incisão abdominal subcostal bilateral . A retrocavidade deve ser exposta por secção entre ligaduras do epíploon gastrocólico. Manobra de Kocher com ampla mobilização do bloco duodenopancreático deve sempre ser realizada, sendo o pâncreas isolado em toda a sua extensão, possibilitando não só a pal pação bidigital como a visualização de todo o órgão.

Após palpação cuidadosa e identificação, ou não, das lesões, temos utilizado, recentemente, ultra-sonografia intra-operatória para local ização de outras lesões. O processo uncinado deve ser palpado cuidadosamente desde que parcela não desprezível desses tumores (12,7\%) esteja localizada nesse segmento do órgão. Além da local ização da lesão, ou lesões, a ultra-sonografia intra-operatória permite o delineamento dos vasos sanguíneos e estruturas ductais, o que permite ao cirurgi ão escolher entre a enucl eação e a ressecção das lesões localizadas no corpo e cauda?

Nos doentes com tumor localizado profundamente no corpo e cauda do pâncreas nas proximidades do ducto de Wirsung foi praticada esplenopancreatectomia distal, que foi realizada em 28 doentes. Recentemente, nos últimos cinco casos, a ressecção do pâncreas distal passou a ser executada com preservação do baço - porém, com técnica diversa da utilizada por outros autores, que ligam a artéria e veias esplênicas ${ }^{28}-$, pois efetuamos dissecção cuidadosa do pâncreas, com preservação da artéria e veias esplênicas.

A enucleação foi realizada em 29 casos e se constitui, atual mente, no método de escol ha não só nos tumores localizados na cabeça do pâncreas como, também, nos local izados perifericamente no corpo e cauda. A ultra-sonografia intra-operatória deve ser utilizada para localizar o ducto de Wirsung, evitando, assim, sua lesão durante a enucleação, o que obrigaria à realização de pancreatectomia.

A duodenopancreatectomia deve ser reservada para casos de insulinomas malignos e nos insu- 
linomas benignos de grandes dimensões, quando a lesão se localiza próximo aos ductos biliares e pancreáticos, ou, então, como aconteceu em um caso de nossa experiência, nas situações de reoperações com lesão prévia dos ductos biliar e pancreático.

Em nenhum caso foi realizada pancreatectomia distal às cegas, o que se consti tui em procedi mento atualmente contra-indicado por vários autores 3,9,17.

Alguns, no entanto, acreditam que a ressecção pancreática, mesmo sem a exata localização das lesões durante a intervenção, somente teria a indicação quando nos estudos pré-operatórios, mediante colheita de amostras de sangue portal, localizou-se a lesão em um determinado segmento do órgão ${ }^{17,29}$. Na literatura, a mortalidade operatória varia de 0 a $6 \%^{3}$. No presente estudo, não se observou óbito pós-operatório imediato. Observaram-se, no entanto, fístulas pancreáticas em 29 casos, sendo definidas como tal toda drenagem de secreção com níveis el evados de amilase, tendo a grande mai oria dos casos apresentado débito menor do que $40 \mathrm{~mL}$ por dia.

Nas situações de enucleação de insulinomas grandes localizados na cabeça do pâncreas, a ultra-sonografia intra-operatória deve ser utilizada para servir de guia na localização dos ductos biliar e pancreático, evitando a lesão do colédoco intrapancreático, como aconteceu em um dos doentes. É necessária, no entanto, a obtenção de colangiografia intra-operatória após a exérese de tais lesões.

$\mathrm{Na}$ aval iação tardia, três doentes $(10,7 \%)$ desenvolveram diabetes, o que motivou a revisão da possibilidade de se efetuar ressecção segmentar do pâncreas ou, mesmo, evitar a ressecção pancreática na grande maioria dos doentes. Nos últimos casos, a utilização de ultra-sonografia intra-operatória tem possibilitado a enucleação de lesões localizadas no corpo e cauda do pâncreas que, anteriormente, eram tratadas por meio de ressecções pancreáticas.

Dos doentes com tumor maligno, apenas um está vivo 15 anos após a cirurgia. Todos os outros faleceram de hipogl icemia menos de dois anos após a intervenção seguida de quimioterapia e embolização da artéria hepática.

Dentre os 55 doentes com insulinoma benigno, 51 estão hoje absolutamente assintomáticos, com glicemia normal, o que resulta em $92,7 \%$ de resultados excel entes. Três doentes estão com glicemia acima do normal, enquanto um doente apresentou recidiva tardia com hipoglicemia leve. Considerando apenas os resultados do tratamento da hipoglicemia em si, incluindo, portanto, os três com diabetes tardio, chega-se a $98,1 \%$ de bons resultados. Estes dados estão em concordância com os da li teratura, que referem $80-99,5 \%$ de bons resultados ${ }^{3}$.

Em conclusão, a localização pré-operatória dos insulinomas, embora desejável, não é absolutamente necessária . A palpação bidigital, associada a ultra-sonografia intra-operatória, é capaz de localizar todas as lesões, principalmente nos casos de reoperações. A enucl eação deve ser utilizada de preferência às ressecções pancreáticas, no sentido de reduzir a incidência tardia de diabetes.

Nesse sentido, a ultra-sonografia intra-operatória fornece os dados anatômi cos necessários para a localização das lesões, propiciando a realização de cirurgia com menor risco de lesões de grandes ductos e vasos sanguíneos.

\section{SUMMARY}

\section{Surgical treatment of insulinoma. Study of 59 cases}

After establishing the diagnosis of an insulinoma the next step is its localization in order to perform the most suitable management approach.

Purpose. To evaluate the methods used for the diagnosis of insulinoma and the localization of its site as well as the results of the surgical treatment.

Methods. Fifty nine consecutive patients with pancreatic insulinomas were studied. The discriminative power of the preoperative investigations in the localization of insulinomas was analysed. Special attention was focused to the intra operative methods of tumor localizations. The early and late results of the surgical treatment were also investigated.

RESULts. There were 55 benign cases and 4 malignant tumors. Preoperative localization was attempted by using ultrasonography (positive in $28.1 \%$ ) CT imaging (positive in $25 \%$ ), selective arteriography (positive in 54.1\%), endoscopic ultrasonography (positive in $27.2 \%$ ) and assay of portal plasma insulin levels (positive in 94.4\%). I n 54/ 55 cases (98.2\%) the tumors were identified intraoperatively by palpation. By addition of intraoperative ultrasonography all lesions were identified and successfully removed without mortality. Five patients had multiple endocrine neoplasias all with multiple lesions in the pancreas.

In patients with benign lesions 29 enucleations and 32 resections were performed. Pancreatic fistulas were the most common complication (29/59).

Excluding the patients with malignant lesions the recovery rate was $98.1 \%$. Three patients who 
underwent corporo caudal pancreactectomy developed diabetes.

Conclusions. The preoperative localization is not necessary, since a combination of palpation and intraoperative ul trasonography can deal with most cases.

E nucl eation when possible is the best choice for benign lesions. [Rev Ass Med Brasil 1998; 44(2): 159-66.]

KEY WORDS: Pancreatic tumors. Islet cell tumors. Hypoglicemia

\section{REFERÊNCIAS BIBLIOGRÁFICAS}

1. Wilder RM, Allan FN, Power $\mathrm{MH}$ et al. Carcinoma of the islands of the pancreas: hyperinsulinism and hypoglycemia. J AMA 1927; 89: 348-55.

2. Edis AJ , MC Trath DC, Van Heerden J A et al. Insulinomas: current diagnosis and surgical treatment. Curr Probl Surg 1976; 13: 1-49.

3. Menegaux $F$, Schmidt, G, Mercadier $M$ et al. Pancreatic insulinomas. AmJ Surg 1993;165: 243-8.

4. Daggett PR, Goodburn EA, Kurtz AB. Is pre operative localization of insulinomas necessary? Lancet 1981; 1: 483-6.

5. Gorman B, Charboneau J W, J ames EM. Benign pancreatic insulinomas: preoperative and intraoperative sonographic localization. AmJ Radiol 1986; 147: 929-34.

6. Galiber AK, Reading CC, Charboneau J W et al. L ocalization of pancreatic insulinoma: comparison of pre-and intraoperative US with CT and angiography. Radiology 1988; 166: 405-8.

7. Gianello P, Gigot J F, Berthet F et al. Pré- and intraoperative Iocal ization of insulinomas: report of 22 observations. World J Surg 1988;12: 389.

8. Service FJ, MC Mahon MM, O'Brien PC et al. Functioning insulinoma - incidence, occurrence and long-term survival of patients - a 60 year study. Mayo Clin Proc 1991; 66: 711-9.

9. Van Heerden J A, Grant CS, CzakoPF et al. Occult functioning insulinomas: which localizing studies are indicated? Surgery 1992; 112: 1.010-5

10. Stefanini $\mathrm{P}$, Carboni $\mathrm{M}, \mathrm{Patrassi} \mathrm{N}$ et al. Beta-islet cell tumor of the pancreas. Results of a study of 1,067 cases. Surgery 1974; 75: 597-609.

11. Grama P, Skogseid B, Wilander E et al. Pancreatic tumor in multiple endocrine neoplasia typel: clinical presentation and surgical treatment. World J Surg 1992; 16: 611-9.

12. Liberman $B, N$ eves GRA, Wajchenberg $B L$ et al. Insulin and $C$ - peptide concentration in portal and peripheral blood in patients with insulinomas. Arq Bras Endocrinol Metabol 1986; 30: 81-84.

13. Machado MCC, Cunha J EM, Bacchella T et al. A modified technique for the reconstruction of the al imentary tract after pancreatoduodenectomy. Surg Gynecol Obstet 1976; 43: 217.

14. Buchanan KD, J ohnson CF, O'H are MMT. Neuroendocrine tumors - a European view. AmJ Med 1986; 81: 14-22.

15. Galbut DL, Markowitz AM. Insulinoma: diagnosis, surgical management and longterm follow up. AmJ Surg 980;139:68390.

16. Goode AW. Insulinoma. J Royal Soc Med 1989; 82: 383-4.

17. Vinik Al, Delbridge L, Moaltari R et al. Transhepatic portal vein catheterization for local ization of insulinomas: a ten year experience. Surgery 1991; 109: 1-11.

18. Van Heerden J A, Edis AJ, Service FJ. The surgical aspects of insulinoma. Ann Surg 1979;189: 677-81.

19. Norton J A, Sigel B, Baker AR. Localization of an occult insulinoma by intraoperative ultrassonography. Surgery 1985; 97: 381-4.

20. Angelini L, Bezzi M, Tucci G. The ultrasonic detection of insulinomas during surgical exploration of the pancreas. World J Surg 1987; 11: 642-7.

21. Klotter HJ , Ruckert K, Kummerle F. The use of intra operative sonography in endocrinetumors of the pancreas. World J Surg 1987; 11: 635-41.

22. Ingemansson $S$, Lunderquist $A$, Lundquist I. Portal and pancreatic vein catheterization with radio-immunologic determination of insulin. Surg Gynecol Obstet 1975; 141: 705-8.

23. Norton J A, Shawker TH, Doppman J L. Localization and surgical treatment of occult insulinomas. Ann Surg 1990; 212: 615-20.

24. Grant CS, Van Heerden J , Charboneau W et al. Insulinoma. Arch Surg 1988; 123: 842-48.

25. Rasbach DA, Van Heerden J A, Telander RL et al. Surgical management of hyperinsulinism in the multiple endocrine neoplasia type I Syndrome. Arch Surg 1985; 120: 584-9.

26. Skogseid B, Grama D, Rastad J et al. Operative tumour yield obviates preoperative pancreatic tumour localization in multiple endocrine neoplasia type I. J I nt Med 1995; 238: 281-8.

27. Thompson NW. The surgical management of hyperparathyroidism and endocrine disease of the pancreas in the multiple endocrine neoplasia type I patient. J I nt Med 1995; 238: 269-80.

28. Cooper MJ , Williamson RC. Conservative pancreatectomy. $\mathrm{Br}$ J Surg 1985; 72: 801-3.

29. Pedrazzoli S, Pasquali C, Mioho D et al. Transhepatic portal sampling for preoperative localization of insulinomas. Surg Gynecol Obstet 1987;165: 101-6. 